\title{
Rwanda hikes premiums in health insurance overhaul
}

L

ong lauded for providing comprehensive health insurance to its people at rock-bottom cost despite being one of the world's poorest nations, Rwanda is in the midst of retooling its health care system to rely less on foreign aid and more on premiums paid directly by citizens to keep the regime economically viable.

The sub-Saharan nation is shelving its former policy of voluntary participation and flat rate premiums in favour of a new compulsory community-based insurance scheme in which premiums paid by citizens will be stratified and more directly based upon ability to pay.

The changes include a threefold increase in the minimum premium for the lowest tier of coverage, which some believe will be untenable for many of the country's poor. Premiums under the new scheme will range from RWF 3000 to RWF 7000 (about $\$ 5$ to $\$ 12$ ) per person. Previously, those on the health insurance system's lowest tier paid a flat rate of RWF 1000 (under \$2) per person, with many of the poorest Rwandans unable to pay even that amount (www.grandslacs.net/doc/4062.pdf).

The voluntary, flat-rate scheme was never meant to be permanent, argues Rwanda's Minister of Health Dr. Agnes Binagwaho. Rather, it was adopted for simplicity's sake when the government first introduced the concepts of health insurance and prepayments in 1996.

"It was a process to convince people to pay in advance in case they are sick. That was not in the culture or the mentality, let alone more complex schemes," she explains. "What people were paying and will be paying is still far below what they're using. It's not normal for government to give subsidies at the same time for those who can pay and those who cannot pay. We are going to put the system in danger."

Rwanda's lowest tier of health insurance covers basic care at local health centres, including such services as vaccinations, family planning, simple childbirth, nutritional services,

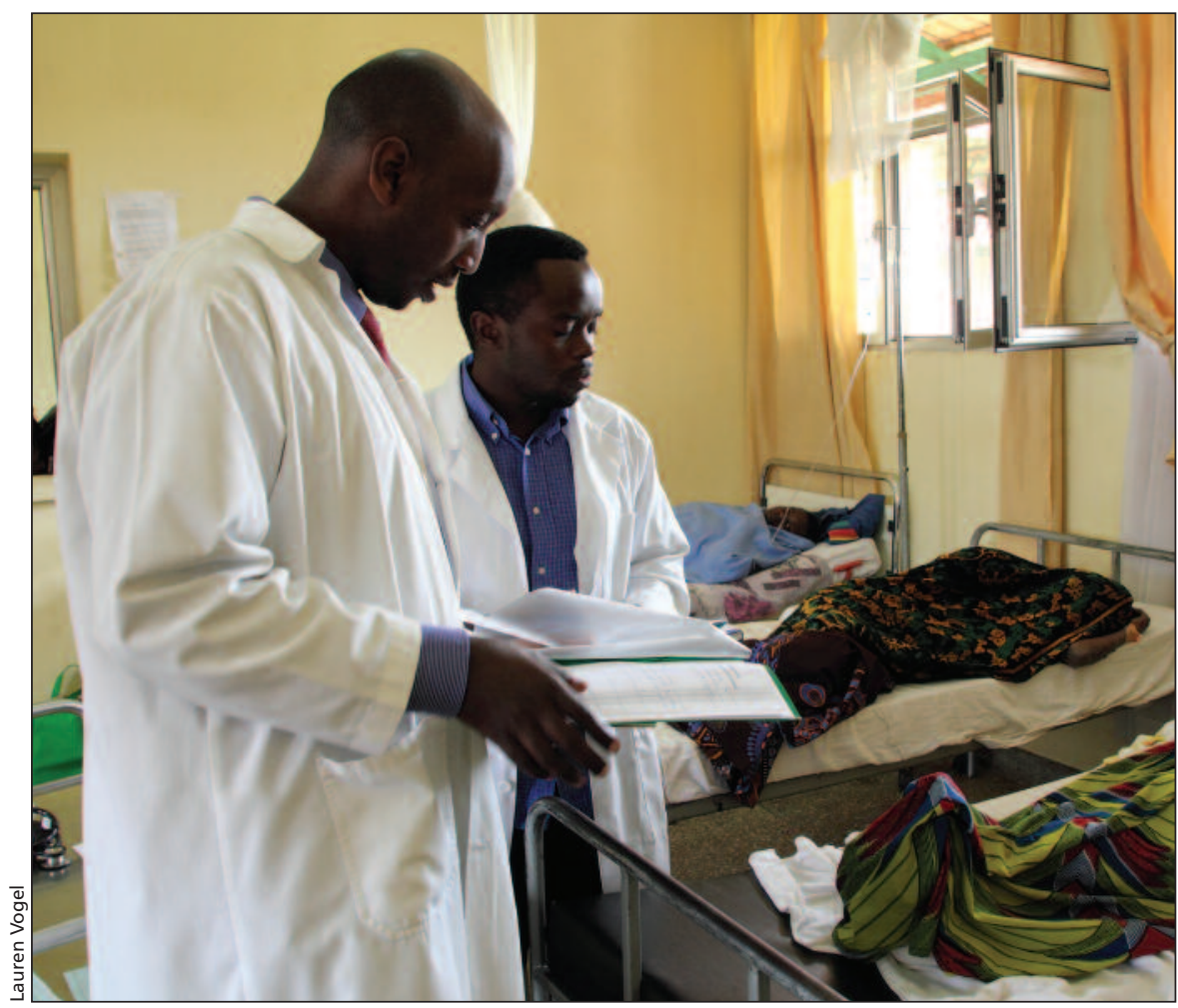

The true cost of health services, such as those provided at Kibagabaga Hospital in Kigali, Rwanda, have yet to be covered by the country's health insurance scheme.

essential and generic drugs, nursing care, minor surgical operations and transportation to a district hospital for more intensive care. The government estimates that the average cost of treating a new case of disease at that level of care is about RWF 1000, while the average cost of hospitalization for eight days is estimated at about RWF 9000.

Total health care spending in Rwanda has risen sharply in recent years, as it has moved from being a country with one of the lowest shares of gross domestic product spent on health (4\% in 2000) to one of the highest in Africa (more than 10\% in 2010), according to the Global Fund to Fight HIV/AIDS, Tuberculosis and Malaria.

Foreign aid accounts for about onethird of Rwanda's gross domestic product (\$US12.16 billion in 2010, according the Central Intelligence Agency World Factbook, https://www.cia.gov /library/publications/the-world-factbook /geos/rw.html), which is one of the highest rates in sub-Saharan Africa. The government of Rwanda indicated in its national budget that it will receive about US\$444 million in capital and current grants from foreign governments and international organizations in 2011-12 (www.minecofin.gov.rw /webfm_send/2216). That includes US\$44 million from the Global Fund.

In the past, the Global Fund has contributed over US\$20 million in support for health insurance subscriptions, says spokeswoman Marcela Rojo.

But Binagwaho says patients have taken advantage of the heavily subsidized system and are overusing limited resources. With some $91 \%$ of the Rwandan population now covered by the mandatory minimum of insurance, up from just $7 \%$ in 2003, utilization of primary health care services has spiked to about $95 \%$ from just $24.7 \%$ in 2001 
(www.moh.gov.rw/index.php?option= com_docman\&task=doc_download\& gid=223\&Itemid=13).

Now that Rwandans are familiar with the concept of prepayment for health care, the country must regularly revise premium levels to keep the system financially sustainable, Binagwaho says. "The government will still have the same responsibilities for people living in extreme poverty" and will continue to subsidize their premiums through block grants to administrative districts.

More than 600000 of the poorest Rwandans in 2010 were subsidized with payments of RWF 1000 to help them buy insurance. It remains to be seen whether government subsidies for the poor will increase to cover the full cost of higher premiums under the new regime.

Under that system, where a person fits on the economic spectrum, and how much that person will have to pay for health insurance, will be determined using household statistics culled from a national database designed to target communities for poverty reduction efforts, Binagwaho says.

Each community will be responsible for continually updating the economic status of its members. But problems may arise as a recently concluded pilot of the new insurance regime indicated that some of the data is inaccurate.

"There are people who don't want to be seen as the poorest of the poor, so they wanted to be placed in the middle strata even though they couldn't afford the associated premiums," Binagwaho says. "And of course there was a village where everybody ranked themselves among the poorest of the poor, just to pay less."

Rwandans have until January to contest their status (and therein, their premium levels) within the database. Lauren Vogel, CMAJ

CMAJ 2011. DOI:10.1503/cmaj.109-3956 